\title{
Metabolic and hormonal interactions between muscle and adipose tissue
}

\author{
Eva Tomas ${ }^{1}$, Meghan Kelly ${ }^{1}$, Xiaoqin Xiang ${ }^{1}$, Tsu-Shuen Tsao ${ }^{3}$, Charlotte Keller ${ }^{2}$, Pernille Keller ${ }^{2}$, \\ Zhijun Luo ${ }^{1}$, Harvey Lodish ${ }^{3,4}$, Asish K. Saha ${ }^{1}$, Roger Unger ${ }^{5}$ and Neil B. Ruderman ${ }^{1 *}$ \\ ${ }^{1}$ Department of Medicine, Physiology and Biophysics and Diabetes Unit, Boston University Medical Center, \\ Boston, MA, USA \\ ${ }^{2}$ The Copenhagen Muscle Research Center, University of Copenhagen, Copenhagen, Denmark \\ ${ }^{3}$ Whitehead Institute for Biomedical Research and \\ ${ }^{4}$ Massachusetts Institute of Technology, Boston, MA, USA \\ ${ }^{5}$ University of Texas Southwestern Medical Center and Veterans Affairs Medical Center, Dallas, TX, USA
}

\begin{abstract}
From the perspective of a muscle physiologist, adipose tissue has long been perceived predominantly as a fuel reservoir that provides muscle and other tissues with NEFA when exogenous nutrients are insufficient for their energy needs. Recently, studies have established that adipose tissue is also an endocrine organ. Among the hormones it releases are adiponectin and leptin, both of which can activate AMP-activated protein kinase and increase fatty acid oxidation in skeletal muscle and probably other tissues. Deficiencies of leptin or leptin receptor, adiponectin and IL-6 are associated with obesity, insulin resistance and a propensity to type 2 diabetes. In addition, a lack of adiponectin has been linked to atherosclerosis. Whether this pathology reflects a deficient activation of AMP-activated protein kinase in peripheral tissues remains to be determined. Finally, recent studies have suggested that skeletal muscle may also function as an endocrine organ when it releases the cytokine IL-6 into the circulation during sustained exercise. Interestingly, one of the apparent effects of IL-6 is to stimulate lipolysis, causing the release of NEFA from the adipocyte. Thus, hormonal communications exist between the adipocyte and muscle that could enable them to talk to each other. The physiological relevance of this cross talk clearly warrants further study.
\end{abstract}

\section{Adiponectin: IL-6: AMP-activated protein kinase: Malonyl-CoA:} Energy homeostasis: Insulin resistance

For much of the past 50 years adipose tissue has been principally viewed as a fuel reservoir that supplies NEFA for the energy requirements of other tissues and skeletal muscle as a more or less passive recipient of this largesse. From the perspective of a muscle physiologist, the adipocyte has been considered to play a particularly important role during starvation and exercise (Fig. 1(a)) when it increases the release of NEFA in keeping with the fuel needs of the muscle cell. These perceptions have slowly begun to change following the discovery that adipose tissue also functions as an endocrine organ (Spiegelman \& Flier, 2001) and, more recently, the realization that skeletal muscle may assume a similar role during exercise (Keller et al. 2001).

Adipose tissue releases over twenty substances into the circulation (Gong et al. 2003), which perhaps makes it the champion endocrine organ, at least for the present. Of these hormones, leptin and adiponectin have been the most intensively studied (Fig. 1(b)). In the present review, the following questions will be addressed: (1) do leptin and adiponectin act on skeletal muscle and if so, how; (2) what happens to muscle and other tissues when these hormones are deficient; (3) does muscle also function as an endocrine organ. The emphasis will be on known factors released by adipose tissue and skeletal muscle and their effect on the fuel-sensing enzyme AMP-activated protein kinase (AMPK).

\section{Leptin}

It has been appreciated since its discovery (Halaas et al. 1995) that leptin diminishes adiposity both by depressing food intake and increasing peripheral energy expenditure. Recently, leptin has been shown to increase fatty acid

\footnotetext{
Abbreviations: AICAR, 5-amino-4-imidazolecarboxamide riboside; AMPK, AMP-activated protein kinase; gAcrp30, the globular subunit of the adiponectin molecule.

*Corresponding author: Professor N. B. Ruderman, fax +1 6176387094 , email nruderman@medicine.bu.edu
} 
(a)

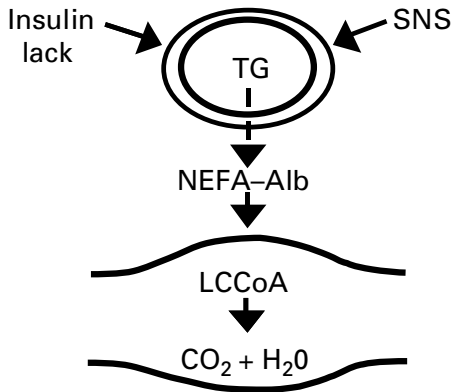

(b)

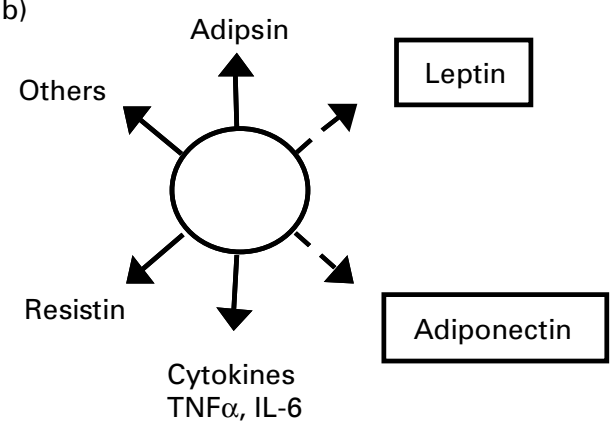

Fig.1. (a) Adipocyte as a fuel reservoir for muscle during starvation (insulin lack) and exercise. SNS, sympathetic nervous system; TG, triacylglycerols; LCCoA, long-chain fatty acyl-CoA; Alb, albumin. (b) Adipocyte as an endocrine organ.

oxidation in skeletal muscle (Muoio et al. 1999) and to prevent lipotoxicity (the adverse effects caused by the ectopic deposition of lipid in liver, skeletal and cardiac muscle and the pancreatic islets; Lee et al. 1994). In addition, it has been shown that many obese individuals are resistant to leptin (Gong et al. 2003). In the past year studies by Kahn and her co-workers (Minokoshi et al. 2002) have established that leptin may cause these effects by activating the fuel-sensing enzyme AMPK (Fig. 2). Thus, they have shown that infusion of leptin intravenously leads to a transient increase in AMPK activity in skeletal muscle that peaks at $15 \mathrm{~min}$, and a later more sustained increase that persists for upwards of $6 \mathrm{~h}$. They have postulated that the early effect is the result of a direct action of leptin on muscle and the later effect is a result of a central action on the hypothalamus that increases sympathetic nervous system activity. In keeping with this contention, the sustained increase in AMPK activity has been observed when leptin is administered centrally as well as peripherally, and it is markedly diminished both by denervating the muscle and by treating the rat with the $\alpha$ adrenergic antagonist phentolamine (Minokoshi et al. 2002).

Preliminary data (X Yu, R Unger, AK Saha and NB Ruderman, unpublished results) suggest that the effects of leptin on AMPK may extend to tissues other than muscle. In the Zucker diabetic rat, a rodent with obesity and ectopic lipid deposition as a result of a genetic deficiency of leptin receptors (Lee et al. 1994), it has been found that treatment for 13 weeks with the AMPK activator 5-amino4-imidazolecarboxamide riboside (AICAR) markedly diminishes $(80 \%)$ the accumulation of fat in liver, muscle
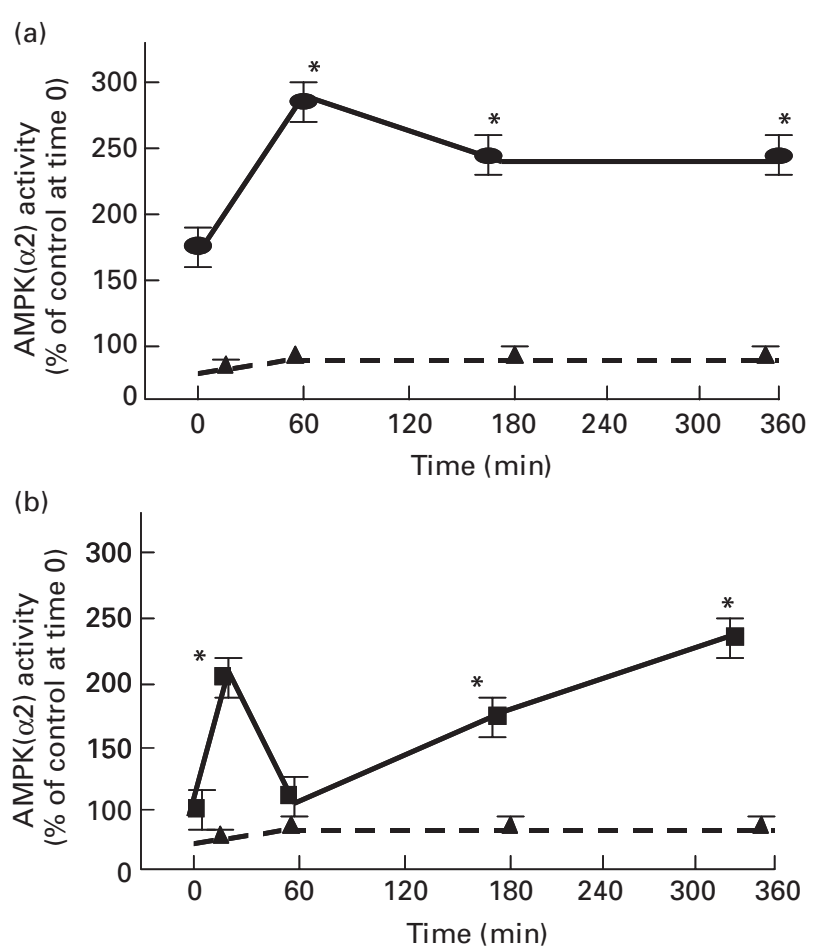

Fig. 2. AMP-activated protein kinase (AMPK) activation in rat soleus muscle after injection of leptin intrahypothalamically $(\mathrm{a}$; or intravenously (b; $\mathbf{\square})$. $(\boldsymbol{\Delta}-\cdots \mathbf{\Delta})$, Saline $(9 \mathrm{~g} \mathrm{NaCl} / \mathrm{l})$. Values are means with their standard errors represented by vertical bars. Mean value was significantly different compared with the saline injection: ${ }^{*} P<0.05$. (Adapted from Minokoshi et al. 2002.)

and the pancreatic $\beta$-cell and prevents the development of diabetes. Presumably, AMPK activation in each of these tissues accounts for the effects of AICAR; however, direct evidence for this role is still lacking.

\section{Adiponectin}

Basic description

Another hormone synthesized and released by differentiated adipocytes is the cytokine adiponectin, also termed Acrp30 (Scherer et al. 1995). Adiponectin circulates in plasma predominantly as trimeric, hexameric and highmolecular-weight species (Tsao et al. 2002). In addition, the globular subunit of the adiponectin molecule (gAcrp30), which is not detectable in plasma, has been shown to have biological activity (Fruebis et al. 2001). Early studies have linked adiponectin to energy homeostasis, since the expression of its mRNA is decreased in adipose tissue of obese mice (Hu et al. 1996; Arita et al. 1999) and human subjects (Hotta et al. 2000). In addition, a negative correlation between plasma adiponectin levels, insulin resistance, obesity and a predisposition to diabetes has been repeatedly observed (Hotta et al. 2000; Arner, 2003). More recently, it has been shown that adiponectin knock-out mice show delayed clearance of NEFA in plasma, low levels of fatty acid transport protein 1 mRNA in muscle, high levels of TNF $\alpha$ mRNA in adipose tissue and elevated plasma TNF $\alpha$ concentrations (Maeda et al. 2002). 
(a) EDL incubated muscle
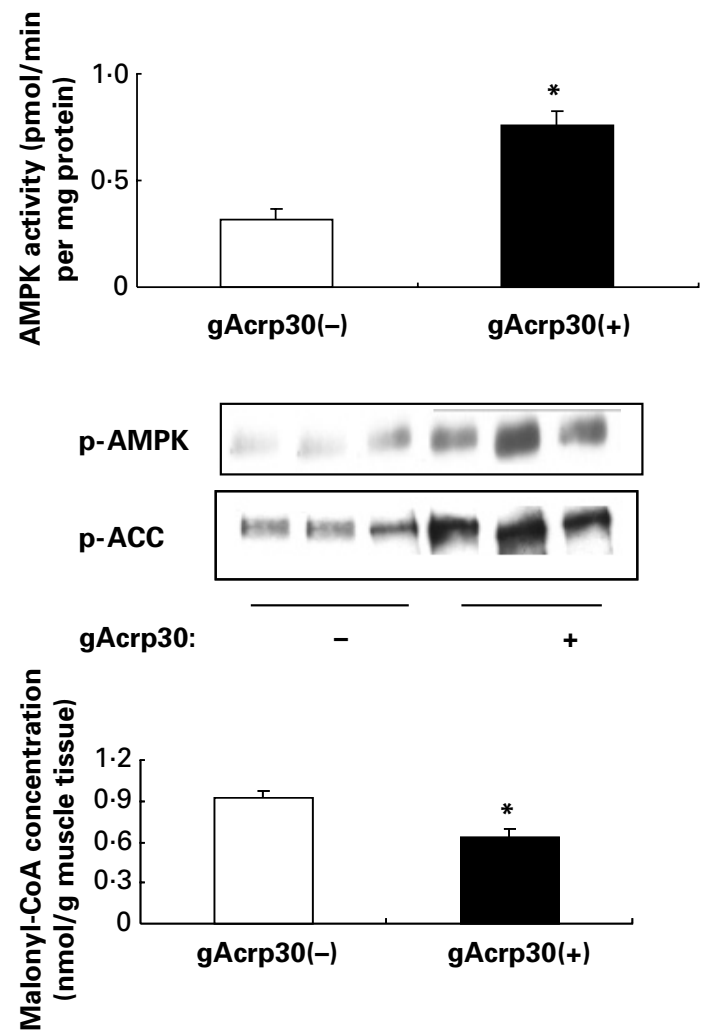

(b) Gastrocnemius muscle in vivo
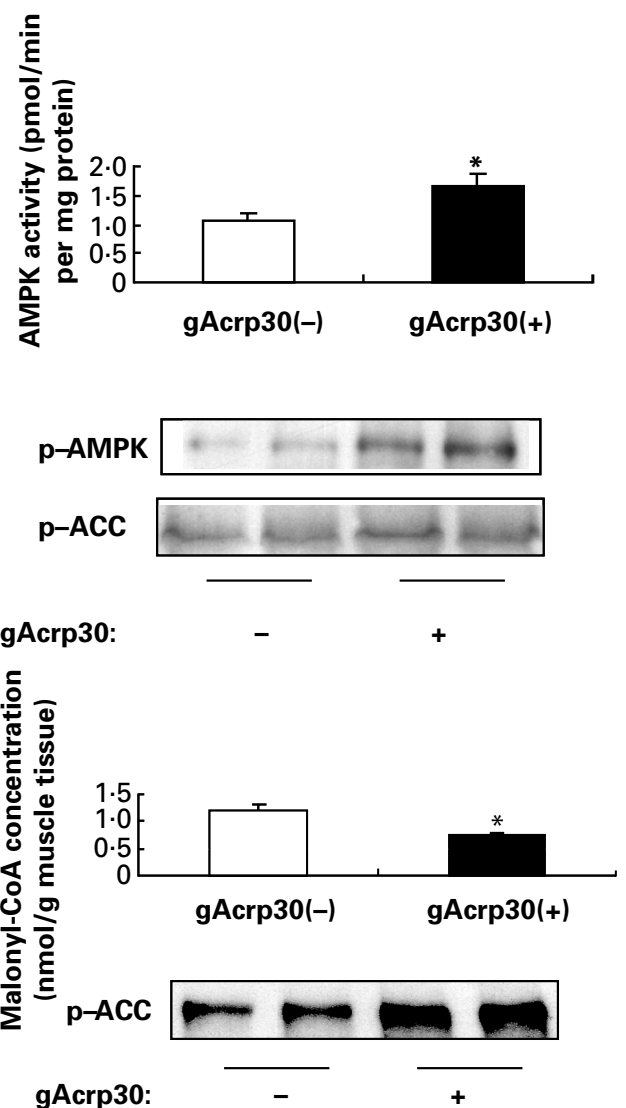

Fig. 3. Effects of globular adiponectin (gAcrp30) on AMP-activated protein kinase (AMPK) and related variables. (a) AMPK activity and phosphorylation ( $\mathrm{p}-\mathrm{AMPK}$ ), acetyl-CoA carboxylase phosphorylation $(p-A C C)$ and malonyl-CoA concentration in rat extensor digitorum longus (EDL) muscles incubated for $30 \mathrm{~min}$ in the presence $(+)$ or absence $(-)$ of gAcrp30 $(2.5 \mu \mathrm{g} / \mathrm{ml})$. (b) Effects of gAcrp30 $(75 \mu \mathrm{g}$ per animal) injected retro-orbitally on the same variables in gastrocnemius muscle of C57BL/6J mice. In both studies $\mathrm{p}$-ACC and malonyl-CoA concentration were altered at $30 \mathrm{~min}$ but not at $15 \mathrm{~min}$. Values are means with their standard errors represented by vertical bars. Mean values were significantly different from those incubated in the absence of gAcrp30: ${ }^{\star} P<0.05$. (Adapted from Tomas et al. 2002.)

Furthermore, when placed on a high-fat high-sucrose diet these mice develop severe insulin resistance, with increased plasma NEFA levels and decreased insulin-stimulated insulin receptor substrate 1 -associated phosphatidylinositol 3-kinase activity in muscle and in cultured myocytes (Maeda et al. 2002). Adiponectin has also been reported to have anti-atherogenic properties. Thus, when either the full-length or gAcrp30 is overexpressed, the atherosclerosis observed in apoE-deficient mice is markedly attenuated (Yamauchi et al. 2001; Okamoto et al. 2002).

Which of the various forms of adiponectin mediate these changes remains to be determined. Fruebis et al. (2001) have demonstrated that purified gAcrp30 (bacterially expressed) increases fatty acid oxidation in incubated mouse muscle and cultured cells. They have also found that when administrated chronically to mice gAcrp30 causes weight loss without diminishing food intake. In contrast, they have found no effect of full-length adiponectin on muscle fatty acid oxidation or plasma NEFA levels (Fruebis et al. 2001). In contrast, in isolated hepatocytes, Berg et al. $(2001,2002)$ have reported that only the full-length adiponectin enhances suppression of glucose production by insulin. It is likely that the different oligomeric isoforms of adiponectin have different signalling activities. Whereas gAcrp30 and the full-length trimer can activate AMPK in muscle, the hexamer and highmolecular-weight adiponectin can only activate NF- $\kappa B$. A similar situation may also exist in other tissue types. Alternatively, these different actions of the two oligomers of adiponectin could be related to the presence of different adiponectin receptors in muscle and liver (Yamauchi et al. 2003).

\section{Molecular signalling induced by adiponectin}

As gAcrp30 has been reported to have the same effects on glucose and lipid metabolism in muscle as exercise and the administration of AICAR, it has been investigated whether it also activates AMPK. Incubation of the extensor digitorum longus muscle with gAcrp30 $(2.5 \mu \mathrm{g} / \mathrm{ml})$ has been shown to lead to a 2-fold increase in the activity of $\alpha 2$ isoform of AMPK, with comparable increases in the 


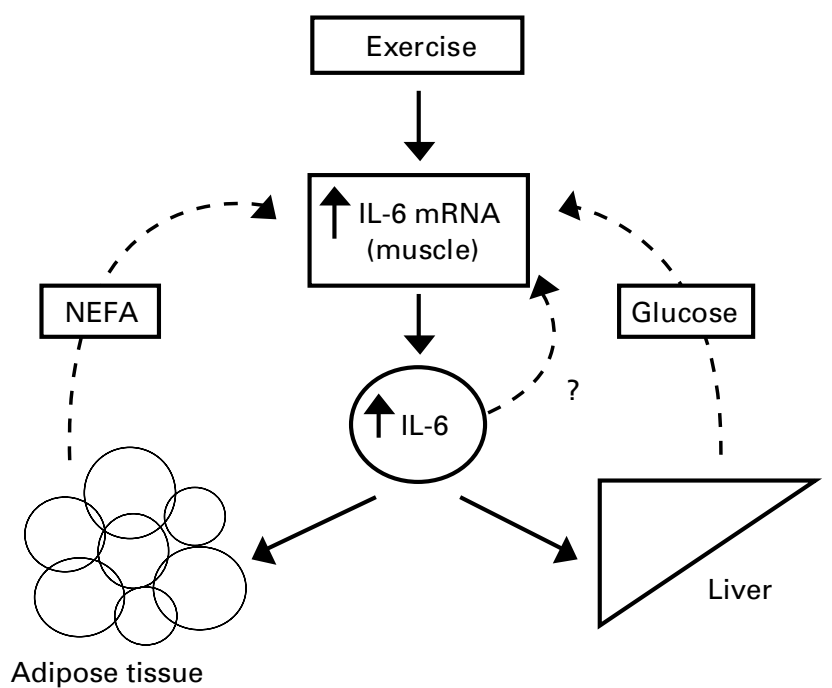

Fig. 4. Proposed actions of IL-6 released from muscle during and after exercise. Not shown is that IL-6 may diminish TNF $\alpha$ expression in muscle. - - Known actions; -...-., less clear, but likely, actions. (Adapted from Steensberg et al. 2002.)

phosphorylation of AMPK and acetyl-CoA carboxylase (Fig. 3) and a 30\% decrease in the concentration of malonyl-CoA (Tomas et al. 2002). Similar findings have been observed after the in vivo administration of gAcrp30 to C57 BL/6J mice (Fig. 3). In both situations the activation of AMPK occurs first and the phosphorylation and inhibition of acetyl-CoA carboxylase occurs later. It has also been shown, in the same studies, that gAcrp30 increases glucose uptake in the absence of added insulin (Tomas et al. 2002), an effect similar to that of AICAR. Similar effects of gAcrp30 have been described by Yamauchi et al. (2002) in C2C12 myocytes and incubated soleus muscle, and by $\mathrm{Wu}$ et al. (2003) in primary rat adipocytes. gAcrp30 has also been shown to reverse the inhibitory effect of TNF $\alpha$ on insulin-stimulated glucose uptake (Wu et al. 2003). The effects of full-length hexameric adiponectin on AMPK activity and acetyl-CoA carboxylase phosphorylation in muscle are controversial (Tomas et al. 2002; Yamauchi et al. 2002). Only fulllength adiponectin appears to activate AMPK in liver (Tsao et al. 2002), consistent with the fact that full-length adiponectin receptor is mainly expressed in liver (Yamauchi et al. 2003).

\section{Muscle as an endocrine organ: IL-6}

There is evidence from Pedersen and her coworkers that muscle can function as an endocrine organ (Fig. 4; see Steensberg et al. 2002). As shown recently, the transcription rate, mRNA level and the release of IL-6 from skeletal muscle are dramatically increased during and after exercise, especially when the exercise is intense and sustained and muscle glycogen content is low (Steensberg et al. 2000; Keller et al. 2001). In addition, further work by Pedersen's group has shown that IL-6, at the concentrations found during exercise, stimulates lipolysis in adipose tissue (Van Hall et al. 2003), and that it can diminish plasma levels of
TNF $\alpha$ (Starkie et al. 2003). In addition, IL-6 deficient mice have been demonstrated to develop late-onset obesity and glucose intolerance (Wallenius et al. 2002). Re-administration of IL-6 results in increased energy expenditure, suggesting an important role of IL-6 in maintaining energy homeostasis. In light of these findings and the earlier observation that $30 \mathrm{~min}$ after a treadmill run AMPK activity is increased in rat liver and adipose tissue as well as in muscle (Park et al. 2002), the effect of IL-6 on AMPK activity in rat tissues has been examined (M Kelly, AK Saha, X Xiang, Z Luo, N Ruderman et al., unpublished results). To date, it has been found that IL-6, at concentrations similar to that observed in plasma during intense exercise, causes 2- to 4-fold increases in AMPK phosphorylation at $\mathrm{Thr}^{172}$ (an index of activation) in both incubated rat extensor digitorum longus muscle and cultured 443A adipocytes. Whether IL-6 exerts these effects in vivo remains to be determined. How these findings relate to the putative linkage between IL-6 and inflammatory events in living organisms will also require further study.

\section{Concluding remarks}

The evidence that the adipocyte hormones leptin and adiponectin can alter fatty acid oxidation and activate AMPK in skeletal muscle has been reviewed. Conversely, IL-6, which is released from muscle during exercise, has been shown to stimulate lipolysis in fat cells and it can activate AMPK in incubated muscle and cultured adipocytes. It must be emphasized, however, that the activation of AMPK by IL-6 has only been observed in vitro. Studies in intact animals are needed to establish whether this effect is physiologically relevant.

\section{References}

Arita Y, Kihara S, Ouchi N, Takahashi M, Meada K, Miyagawa J, Hotta K, Shimomura I, Nakamura I \& Miyaoka K (1999) Paradoxical decrease of an adipose-specific protein, adiponectin, in obesity. Biochemical and Biophysical Research Communications 257, 79-83.

Arner P (2003) The adipocyte in insulin resistance: key molecules and the impact of the thiazolidinediones. Trends in Endocrinology and Metabolism 14, 137-145.

Berg A, Combs TP, Du X, Brownlee M \& Scherer PE (2001) The adipocyte-secreted protein Acrp30 enhances hepatic insulin action. Nature Medicine 7, 947-952.

Berg AH, Combs TP \& Scherer E (2002) ACRP30/adiponectin: an adipokine regulating glucose and lipid metabolism. Trends in Endocrinology and Metabolism 13, 84-89.

Fruebis J, Tsao T-S, Javorschi S, Ebbets-Reed D, Erickson MR, Yen FT, Bihain BE \& Lodish H (2001) Proteolytic cleavage product of $30-\mathrm{kDa}$ adipocyte complement-related protein increases fatty acid oxidation in muscle and causes weight loss in mice. Proceedings of the National Academy of Sciences USA 4, 2005-2010.

Gong D, Yang R, Munir KM, Horenstein RB \& Shuldiner AR (2003) New progress in adipocytokine research. Current Opinion in Endocrinology and Diabetes 10, 115-121.

Halaas JL, Gajiwala KS, Maffei M, Cohen SL, Chait BT, Rabinowitz D, Lallone RL, Burley SK \& Friedman JM (1995) Weight-reducing effects of the plasma protein encoded by the obese gene. Science 269, 543-546. 
Hotta K, Funahashi T, Arita Y, Takahashi M, Matsuda M, Okamoto Y, Iwahashi H, Kuriyama H, Ouchi N \& Maeda K (2000) Plasma concentrations of a novel, adipose-specific protein, adiponectin, in type 2 diabetic patients. Arteriosclerosis, Thrombosis and Vascular Biology 20, 1595-1599.

$\mathrm{Hu}$ E, Liang P \& Spiegelman BM (1996) AdipoQ is a novel adipose-specific gene dysregulated in obesity. Journal of Biological Chemistry 18, 10697-10703.

Keller C, Steensberg A, Pilegaard H, Osada T, Saltin B, Pedersen BK \& Neufer PD (2001) Transcriptional activation of the IL-6 gene in human contracting skeletal muscle: influence of muscle glycogen content. FASEB Journal 15, 2748-2750.

Lee Y, Hirose H, Ohneda M, Johnson JH, McGarry JD \& Unger RH (1994) Beta-cell lipotoxicity in the pathogenesis of noninsulin-dependent diabetes mellitus: impairment in adipocytebeta cell relationships. Proceedings of the National Academy of Sciences USA 91, 10878-10882.

Maeda N, Shimomurs I, Kishida K, Nishizawa H, Matsuda M, Nagaretani H et al. (2002) Diet-induced insulin resistance in mice lacking adiponectin/ACRP30. Nature Medicine 7, 731-737.

Minokoshi Y, Kim YB, Peroni OD, Fryer LG, Muller C, Carling D \& Kahn BB (2002) Leptin stimulates fatty-acid oxidation by activating AMP-activated protein kinase. Nature $\mathbf{4 1 5}$, 339-343.

Muoio DM, Seefeld K, Witters LA \& Coleman RA (1999) AMPactivated kinase reciprocally regulates triacylglycerol synthesis and fatty acid oxidation in liver and muscle: evidence that sn-glycerol-3-phosphate acyltransferase is a novel target. Biochemical Journal 338, 783-791.

Okamoto Y, Kihara S, Ouchi N, Nishida M, Arita Y, Kumada M et al. (2002) Adiponectin reduces atherosclerosis in apolipoprotein E-deficient mice. Circulation 106, 2767-2770.

Park H, Kaushik VK, Constant S, Prentki M, Przybytkowski E, Ruderman NB \& Saha AK (2002) Coordinate regulation of malonyl-CoA decarboxylase, sn-glycerol-3-phosphate acyltransferase, and acetyl-CoA carboxylase by AMP-activated kinase in rat tissues in response to exercise. Journal of Biological Chemistry 277, 32571-32577.

Scherer PE, Suzanne W, Fogliano M, Baldini G \& Lodish HF (1995) A novel serum protein similar to $\mathrm{C} 1 \mathrm{q}$, produced exclusively in adipocytes. Journal of Biological Chemistry 45, 26746-26749.

Spiegelman BM \& Flier JS (2001) Obesity and the regulation of energy balance. Cell 104, 531-543.

Starkie R, Ostrowski SR, Jauffred S, Febbraio M \& Pedersen BK (2003) Exercise and IL-6 infusion inhibit endotoxin-induced TNF-alpha production in humans. FASEB Journal 8, 884-886.

Steensberg A, Keller C, Starkie RL, Osada T, Febbraio MA \& Pedersen BK (2002) IL-6 and TNF-alpha expression in, and release from, contracting human skeletal muscle. American Journal of Physiology 283, E1272-E1278.

Steensberg A, van Hall G, Osada T, Sacchetti M, Saltin B \& Pedersen KB (2000) Production of interleukin-6 in contracting human skeletal muscles can account for the exercise-induced increase in plasma interleukin-6. Journal of Physiology (London) 529, 237-242.

Tomas E, Tsao T-S, Saha AK, Murrey HE, Zhang CC, Itani SI, Lodish HF \& Ruderman NB (2002) Enhanced muscle fat oxidation and glucose transport by ACRP30 globular domain: Acetyl-CoA carboxylase inhibition and AMP-activated protein kinase activation. Proceedings of the National Academy of Sciences USA 99, 16309-16313.

Tsao TS, Murrey HE, Hug C, Lee DH \& Lodish HF (2002) Oligomerization state-dependent activation of NF-kappa B signaling pathway by adipocyte complement-related protein of $30 \mathrm{kDa}$ (Acrp30). Journal of Biological Chemistry 277, 29359-29362.

Van Hall G, Steensberg A, Sacchetti M, Fischer C, Keller C, Schjerling P, Hiscock N, Moller K, Saltin B, Febbraio MA \& Pedersen BK (2003) Interleukin-6 stimulates lipolysis and fat oxidation in humans. Journal of Clinical Endocrinology and Metabolism 88, 3005-3010.

Wallenius V, Wallenius K, Ahren B, Rudling M, Carlsten H, Dickson SL, Ohlsson C \& Jansson JO (2002) Interleukin-6 deficient mice develop mature-onset obesity. Nature Medicine 1, 75-79.

Wu X, Motoshina H, Mahadev K, Stalker TJ, Scalia R \& Goldstein BJ (2003) Involvement of AMP-activated protein kinase in glucose stimulated by the globular domain of adiponectin in primary rat adipocytes. Diabetes 52, 1355-1363.

Yamauchi T, Kamon J, Minokoshi Y, Ito Y, Tsuchida A, Yokomizo T et al. (2003) Cloning of adiponectin receptors that mediate antidiabetic metabolic effects. Nature Medicine 423, 762-768.

Yamauchi T, Kamon J, Minokoshi Y, Ito Y, Waki H, Uchida S et al. (2002) Adiponectin stimulated glucose utilization and fatty-acid oxidation by activating AMP-activated protein kinase. Nature Medicine 11, 1-8.

Yamauchi T, Kamon J, Waki H, Terauchi Y, Kubota N, Hara K et al. (2001) The fat-derived hormone adiponectin reverses insulin resistance associated with both lipoatrophy and obesity. Nature Medicine 8, 941-946. 
https://doi.org/10.1079/PNS2004356 Published online by Cambridge University Press 